\title{
Freeze Drying Plants for the Food and Beverage Industries
}

\author{
${ }^{1}$ G. Sasikala, ${ }^{2}$ Dr. B. Umamaheswara Gowd \\ ${ }^{1}$ Ph.D Scholor, ${ }^{2}$ Rector \& Professor, \\ ${ }^{1,2}$ M. Tech Ph. D. Department of Mechanical Engineering, J N T University, Anantapur
}

\begin{abstract}
Freeze drying is a practical and widely used method for the stabilization of otherwise easily degraded substances, microorganisms, foods, biological products and pharmaceutical products. The purpose of this investigation is to determine the freeze drying plants for the Food and Beverage industries.

Freeze drying is the drying of an already deep-frozen product in a vacuum below the triple point. The vacuum allows the ice to turn directly into vapour without first passing through the water stage, in a sublimation process. This ensures that the product retains most of its original shape, color, taste, and nutrients. Freeze dried products have other advantages too: they have uniform, high quality, a very long shelf life, require no refrigeration during storage, they are light weight, making them easy and inexpensive to transport, and they reconstitute quickly and completely with the addition of water.

That is why freeze dried products are in such great demand and why the freeze drying process is able to add significant value to a wide range of food product including; vegetables, fruit and berries, meat and seafood product; prepared meals including baby food, TV inners, camping provisions, and military rations, and beverages such as tea and coffee. Coffee is by far the biggest single freeze dried food commodity in the world today.
\end{abstract}

\section{Introduction}

Products that are to be freeze dried must be present in deep frozen form. Freeze drying takes place under vacuum condition below the triple point $(6.2 \mathrm{~m}$ bar $=4.6$ torr). Here, water will only be present in two phases: ice and vapor. By adding energy to the ice it will sublimate (evaporate) directly into the vapor phase. The vapor is condensed immediately on vapor traps to maintain the vacuum.

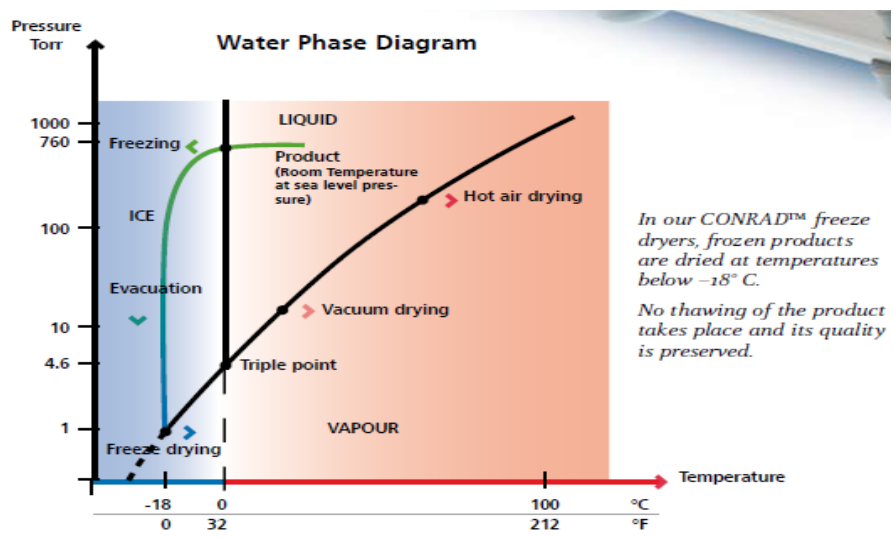

Water vapor has easier access through any product cell structure than water, penetrating the product mass to evaporate from the surface of the product as in the case in other drying methods. The gentle escape of water vapor in the freeze drying process leaves the product close to it original shape with it taste and color preserved and with no loss of aroma. The vacuum and temperature used during the freeze drying depends on the product, its shape, water content, product structure and composition.

\section{Freeze Drying Processes}

The drying process is fundamentally the same for any type of product, but the way in which different products are prepared for drying varies considerably. Product for freeze drying fall into three basic categories: liquids, individually quick frozen (IQF) products and combined products. Preparation for the freeze drying of liquids is the most complex part of the process. First, the liquids is the must be treated to achieve the required density and color characteristics. The concentrate is then frozen slowly on a CAB (continuous Air Blast) freezer, 
alternatively, more quickly on a Rota- freezer or in other freezing device for obtaining a solid frozen form. The product is then granulated and sieved to produce granules of optimum size depending on requirement.

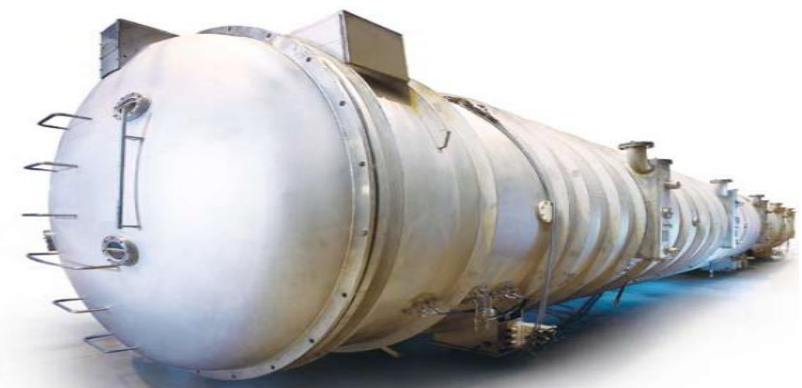

The granules are loaded onto the trays to pass through the freeze dryer. Everything is weighed to ensure the correct volume on each try for perfect freeze drying. The trays are automatically loaded using specially developed try feeder to secure a uniform and accurate filling. IQF products are loaded by weight or volume density on to the trays before passing through the combined product are normally loaded into special plastic moulds placed into the trays defining the bloc size of the product. Freezing takes place in a tray freezer prior to the further automatic transport. Each product has be prepared carefully to ensure it retain its original characteristics and to meet the requirements of the finished product.

\section{Continuous FREEZE DRYING PLANTS}

\begin{tabular}{|c|c|c|c|c|c|c|}
\hline Type CONRAD & & 200 & 300 & 400 & 500 & $2 \times 500$ \\
\hline \multicolumn{7}{|c|}{ Extracts with $45 \%$ dry matter } \\
\hline Capacity input & $\mathrm{kg} / \mathrm{h}$ & 433 & 649 & 866 & 1,082 & 2,165 \\
\hline \multirow[t]{2}{*}{ Capacity output } & $\mathrm{kg} / \mathrm{h}$ & 200 & 300 & 400 & 500 & 1,000 \\
\hline & Output $\mathrm{kg} / 24 \mathrm{~h}$ & 4,800 & 7,200 & 9,600 & 12,000 & 24,000 \\
\hline \multicolumn{7}{|c|}{ Extracts with $25 \%$ dry matter } \\
\hline Capacity input & $\mathrm{kg} / \mathrm{h}$ & 313 & 469 & 625 & 781 & 1,563 \\
\hline \multirow[t]{2}{*}{ Capacity output } & $\mathrm{kg} / \mathrm{h}$ & 81 & 121 & 161 & 201 & 403 \\
\hline & Output $\mathrm{kg} / 24 \mathrm{~h}$ & 1,933 & 2,900 & 3,867 & 4.833 & 9,667 \\
\hline \multicolumn{7}{|c|}{ Solids with $15 \%$ dry matter } \\
\hline Capacity input & $\mathrm{kg} / \mathrm{h}$ & 170 & 256 & 341 & 426 & 852 \\
\hline \multirow[t]{2}{*}{ Capacity output } & $\mathrm{kg} / \mathrm{h}$ & 26 & 40 & 53 & 66 & 132 \\
\hline & Output $\mathrm{kg} / 24 \mathrm{~h}$ & 632 & 948 & 1,264 & 1,580 & 3,161 \\
\hline
\end{tabular}
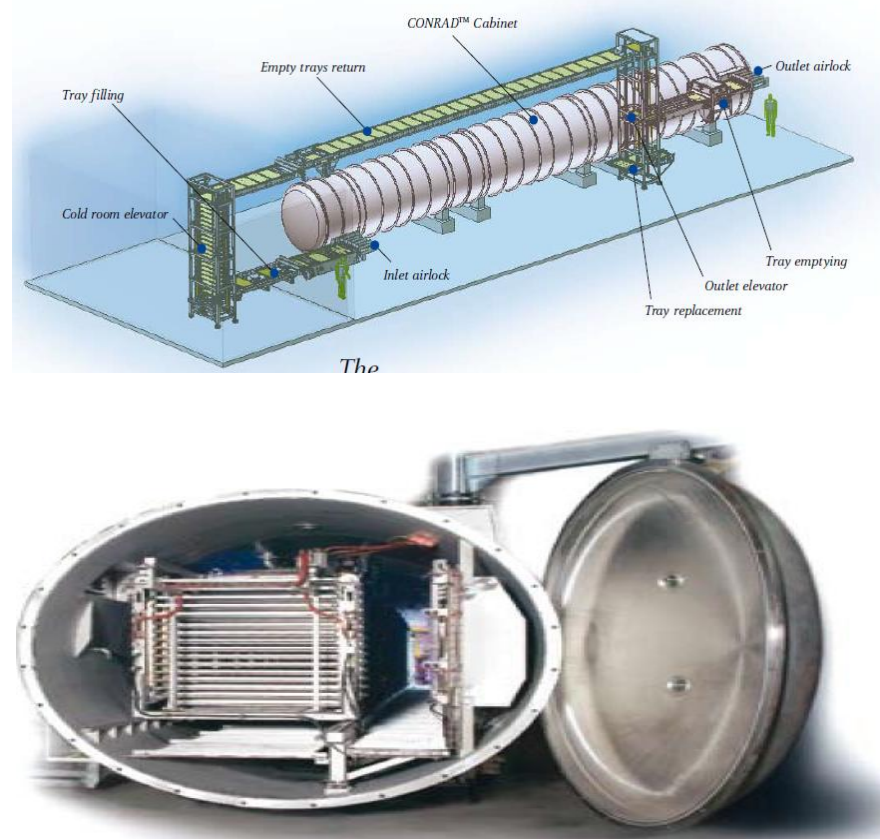

All movement and process parameters are carefully controlled, monitored and logged with the most modern PLC/PC system. Trays with frozen product are loaded into the dryer through an efficient airlock system to an inlet elevator inside the chamber. When the elevator has a full stack of product tray, the entire stack is 
Freeze Drying Plants for the Food and Beverage Industries

pushed into the first drying zone. More stacks follow and are pushed in turn through the various subsequent drying zone of the dryer - each adjusted to provide the drying characteristics required. When trays arrive at the drier exit elevator they are unloaded, again through an airlock, and the product emptied from the trays.

\section{The CDI System}

The vapor from the freeze drying process is collected on the special condensers. In order to ensure a continuous process, all dryers are equipped with a continuous De-Icing (CDI) system that enables automatic deicing of the condensers with no loss of operating vacuum.
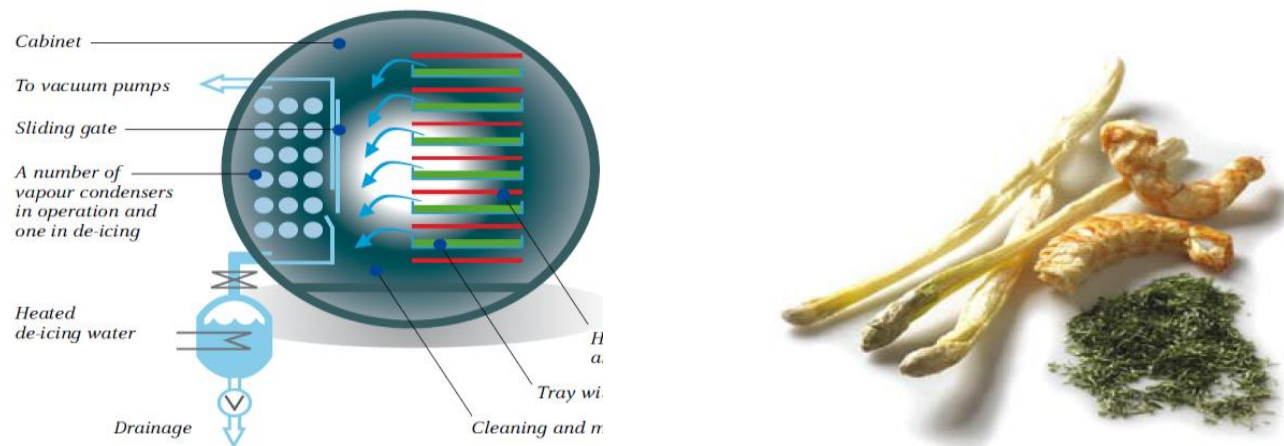

\section{Process at a Glance}

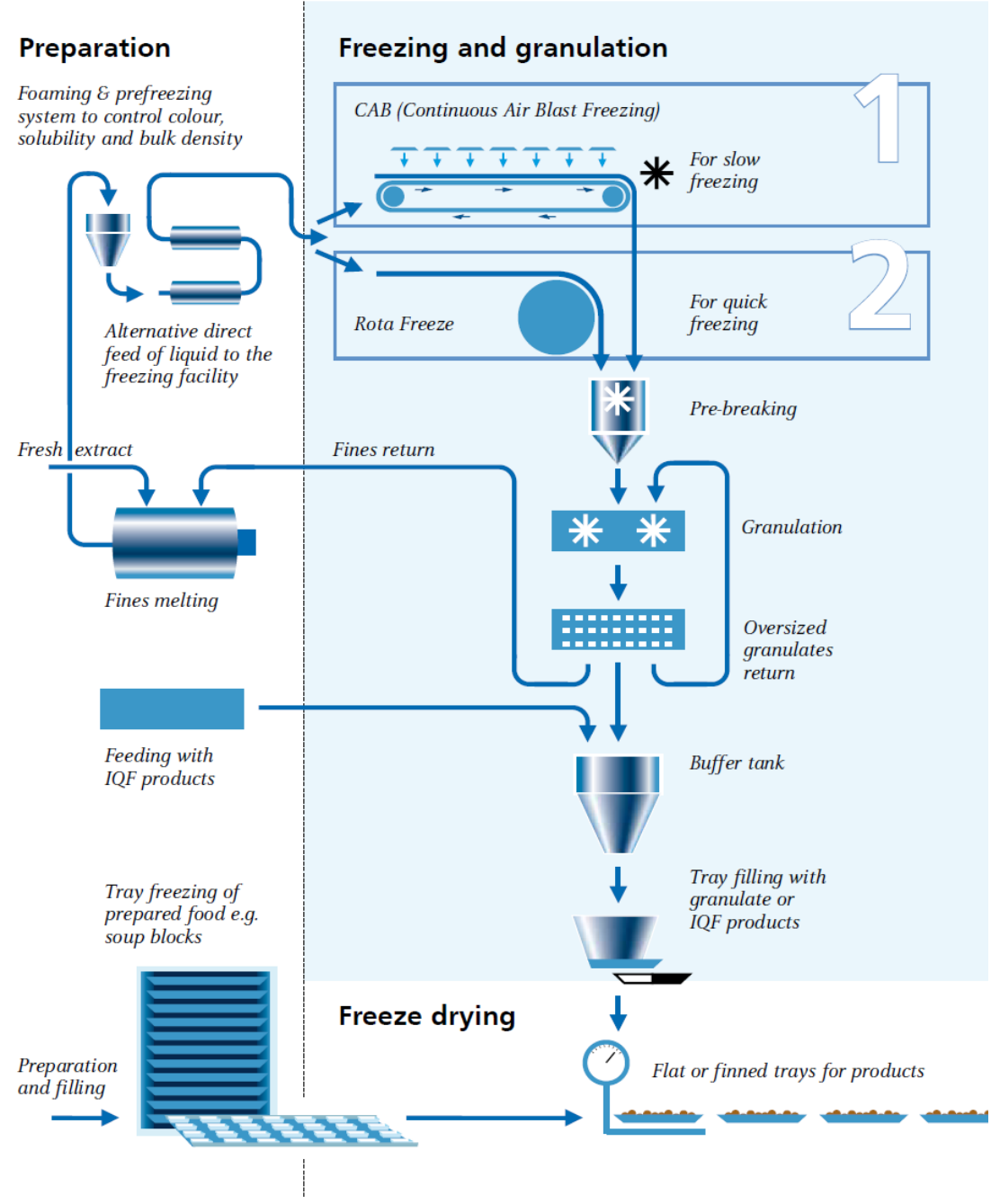


Dimensions

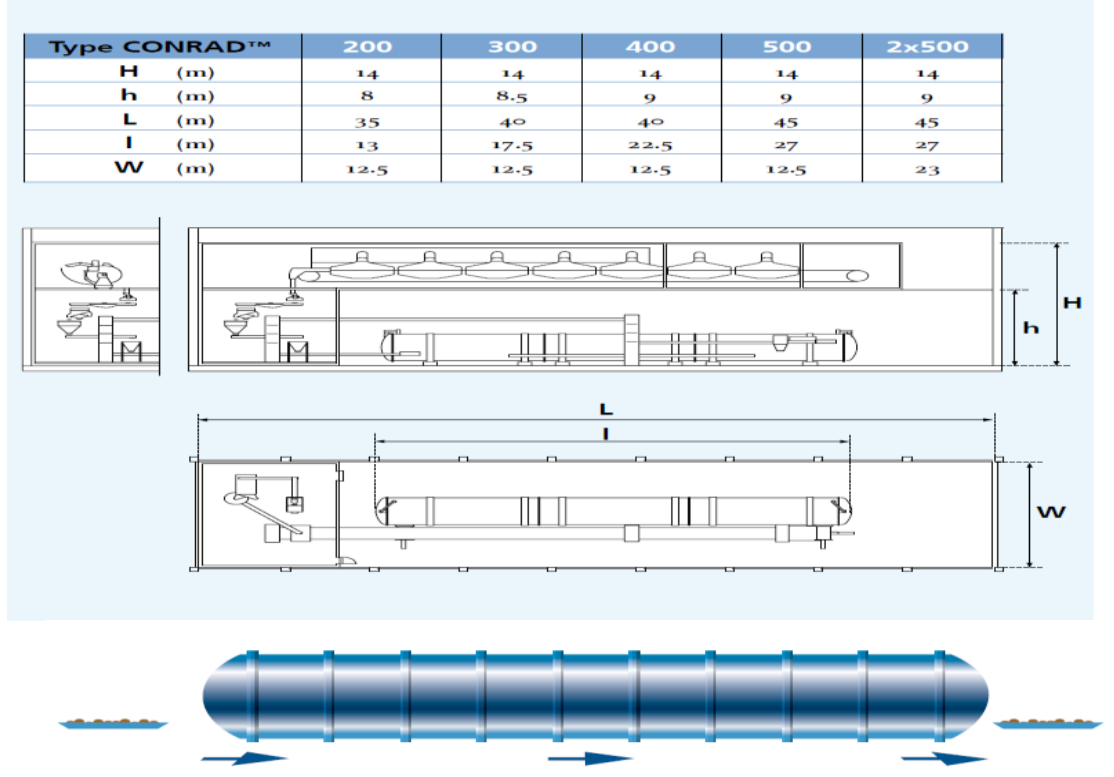

\section{Conclusions}

Freeze drying has often been carried out in an empirical "trail and error" manner. The preceding discussion attempt to show however that every stage of lyophilization is governed by certain principles which need to be understood if the process is to be optimized. The study of thermal events and related phase transitions as well as the use of microprocessors are the foundation to approach rationally the freeze drying process.

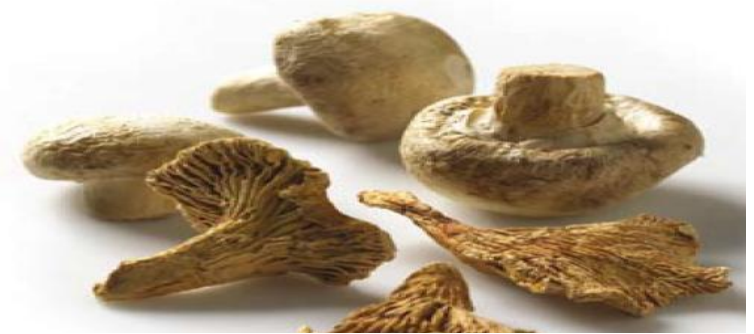

A strict cooperation a food and beverage industries technologist, thermal analysis scientist and the designer of freezer-dryer is essential to achieve the goal a freeze-dried product with best attributes and stability.

\section{Refernces}

[1] B.Uchanan, S., Disaster planning: Preparedness and recovery for libraries and

[2] Archive, Unesco,Paris 1988.

[3] Andersen, L.M, Frysetorring of arkaeo logistrae, onservatorskolen, Detkongelige Danske kunstaademi, kobenhavn, 1993,S.60 -199.

[4] ISO 5630, paper and board, Accelerated ageing, international organization for standardization, Geneve, 1986 \&1991.

[5] Paper stenik, Institutionen for papertekni Kunglinga Tekniska Hogsskolan, Stockholm,1991,P.319.

[6] Cowin,W.F., Short span tensile analysi, pulmac instrument Ltd., Montreal,1975,P.2-9.

[7] Brain Donaldson. Wedding Bouquete preservation aver your special memorie of your wedding day through the preservation of your bridal bouquet. Retrieved 2010.

[8] Dr. J. Jeff Schwegman (2009) Basic cycle Development Technique for lyophilized products.

[9] George- Wilhelm oetjen (1999). Freeze-drying weinheim. Newyouk.

[10] J.D. Meller (1978). Fundamentals of freeze dryers. Acadamic pres London Newyouk SanFrancisco.

[11] Osei Boesh - Ocaney (1988). Freeze -drying in a fluidized bed atmosphericdryers and in a vacuum dryer, Evaluation of external transfer coefficient J. Of Food engineering. Vol-7, pp-127,-146 